\title{
BUROCRACIA COMO ORGANIZAÇ̃̃O, PODER E CONTROLE
}

BUREAUCRACY AS ORGANIZATION, POWER AND CONTROL

BUROCRACIA COMO ORGANIZACIÓN, PODER Y CONTROL

\section{RESUMO}

O objetivo central deste trabalho consiste em analisar a forma como Maurício Tragtenberg e Fernando Cláudio Prestes Motta concebem a burocracia. Os objetivos específicos são: compreender as principais características da burocracia segundo Weber, autor central que orienta as obras de Tragtenberg e de Prestes Motta; atingir o entendimento de burocracia expresso na obra de Tragtenberg; apreender o entendimento de burocracia segundo a obra de Prestes Motta; analisar as relações entre os entendimentos de burocracia de Tragtenberg e de Prestes Motta. São levados em consideração nas análises dos autores e do conceito de burocracia: a trajetória intelectual; a ordem das produções; as epistemologias; o espaço e o tempo histórico; a dimensão semântica, ideológica e cultural; questionamentos que se revelam importantes para se compreender o desenvolvimento teórico do conceito. Chegou-se à conclusão de que, apesar das diferenças nas trajetórias intelectuais de Tragtenberg e Prestes Motta, a burocracia é entendida por ambos como organização, poder e controle.

PALAVRAS-CHAVE Burocracia, poder, controle, Maurício Tragtenberg, Fernando Claudio Prestes Motta.

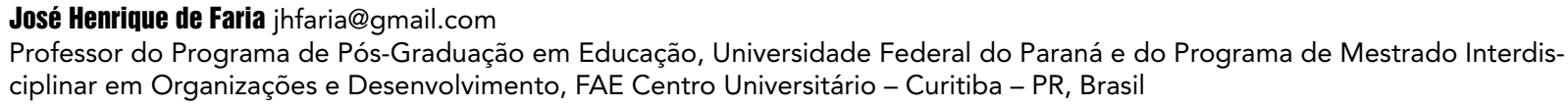

Francis Kanashiro Meneghetti fkmeneghetti@gmail.com

Professor do Departamento de Gestão e Economia, Universidade Tecnológica Federal do Paraná - Curitiba - PR, Brasil

\begin{abstract}
The main objective of this work is to analyze the way in which Maurício Tragtenberg and Fernando Cláudio Prestes Motta conceived bureaucracy. The specific objectives are: to understand the main characteristics of bureaucracy according to Weber, the author who has most influence on the work of Tragtenberg and Prestes Motta; to arrive at an understanding of bureaucracy as expressed in the work of Tragtenberg, to learn how bureaucracy is understood in the work of Prestes Motta and to analyze the relationships that exist between the understanding of bureaucracy in Tragtenberg and Prestes Motta. In analyzing the authors consideration was given to their concept of bureaucracy, their intellectual trajectory, the order of their production, epistemologies, space and historical time, the semantic, ideological and cultural dimension and questions that are important for an understanding of the theoretical development of the concept. The conclusion was reached that, despite the differences in the intellectual paths of Tragtenberg and Prestes Motta, bureaucracy is understood by both as being organization, power and control.

keywords Bureaucracy, power, control, Maurício Tragtenberg, Fernando Claudio Prestes Motta.

Resumen El objetivo central de este trabajo consiste en analizar la manera como Maurício Tragtenberg y Fernando Cláudio Prestes Motta conciben la burocracia. Los objetivos específicos son: comprender las principales características de la burocracia según Weber, autor central que orienta las obras de Tragtenberg y de Prestes Motta; lograr la comprensión de burocracia expresa en la obra de Tragtenberg; aprender la comprensión de burocracia según la obra de Prestes Motta; analizar las relaciones entre entedimientos de burocracia de Tragtenberg y de Pestes Motta. Se tienen en cuenta en las análises de los autores y del concepto de burocracia: la trayectoria intelectual; el orden de las producciones; las epistemologías; el espacio y el tiempo histórico; la dimensión semántica, ideológica y cultural; cuestiones que se presentan importantes para que se comprenda el desarrollo teórico del concepto. Se llegó a la conclusión de que, a pesar de las diferencias en las trayectorias intelectuales de Tragtenberg y Prestes Motta, la burocracia es comprendida por ambos como organización, poder y control.
\end{abstract}

Palabras clave Burocracia, poder, control, Maurício Tragtenberg, Fernando Claudio Prestes Motta. 


\section{INTRODUÇÃO}

A concepção de burocracia tem sido amplamente estudada em diversas áreas do conhecimento (MERTON, 1952; LAPASSADE, 1977). É inegável que a grande contribuição sobre o tema tenha sido realizada por Max Weber (1982), base para vários outros pesquisadores de diversas correntes epistemológicas. Como objeto de estudo nas ciências sociais (sociologia, ciência política, direito, administração), as pesquisas sobre a burocracia resultaram em vários e diferentes entendimentos, como por exemplo: como organização (CAMPOS, 1978; BRESSER-PEREIRA, 1980), como categoria social (POULANTZAS, 1977) ou como poder político (MORIN, 1976; MARTIN, 1978). Na área de estudos organizacionais não tem sido diferente, dada sua característica multidisciplinar.

Nesse sentido, a pergunta que direciona este trabalho é: qual é a concepção de burocracia nos estudos de Maurício Tragtenberg e de Fernando Cláudio Prestes Motta? Desse modo, o objetivo principal desta análise é verificar de que forma Maurício Tragtenberg e Fernando Cláudio Prestes Motta, dois importantes intelectuais da área de estudos organizacionais, concebem a burocracia. Adicionalmente, pretende-se: (i) compreender as principais características da burocracia segundo Weber, autor central que orienta as obras de Tragtenberg e de Prestes Motta; (ii) compreender qual o entendimento de burocracia em Tragtenberg; (iii) verificar qual o entendimento de burocracia em Prestes Motta; (iv) analisar as relações entre os entendimentos de burocracia em Tragtenberg e Prestes Motta.

O artigo é uma contribuição para as áreas de Estudos Organizacionais, Administração Geral e Pública, e para as ciências sociais em geral, dado que o fenômeno da burocracia está presente em todos os âmbitos sociais. Esta contribuição se dá em cinco pontos. Em primeiro lugar, porque há uma tendência em atribuir uma uniformidade em relação ao conceito de burocracia, o que resulta em equívocos sobre as formas que estas tomam nas diferentes relações sociais e de produção das condições materiais de existência. Essas dificuldades também aparecem no campo dos estudos organizacionais críticos. A tendência de atribuir significado único e de não levar em consideração como a burocracia se estrutura e se sedimenta na sociedade cria dificuldades no entendimento desse fenômeno. Isso significa que os estudos que tratam da burocracia na perspectiva da administração devem ter o cuidado de abordá-la em sua materialidade concreta e não apenas abstratamente. Esta é, assim, a primeira contribuição.

Em segundo lugar, Tragtenberg e Prestes Motta são autores cujos estudos influenciaram várias gerações de pensadores em suas áreas de atuação. Tragtenberg, por exemplo, é referência nas áreas de Estudos Organizacionais, de Administração, Ciências Sociais, Educação e na militância política. Prestes Motta influenciou vários pesquisadores e tornou-se uma referencia na área de teoria geral da Administração. Compreender seus estudos é entender as bases conceituais com que se pode olhar criticamente a realidade a partir das reflexões que fizeram. A perspectiva do resgate da história da constituição do pensamento crítico em Administração no Brasil é a segunda contribuição que este estudo pretende oferecer.

Em terceiro lugar, compreender a relação entre burocracia e capitalismo de uma perspectiva ao mesmo tempo materialista-histórica e anarquista a partir de Weber é um desafio epistemológico e teórico. A leitura das contribuições de Tragtenberg e Motta a partir desta perspectiva do diálogo teórico e epistemológico leva a uma compreensão diferente do conceito de burocracia, fortemente influenciado pela perspectiva funcionalista de Talcott Parsons, Merton, entre outros, é a terceira contribuição que este estudo pretende oferecer.

Em quarto lugar, refletir sobre a relação entre burocracia e Estado a partir de uma perspectiva histórica concreta e não de um ponto de vista abstrato e a-histórico, como é mais usual na área de Estudos Organizacionais e da Teoria da Administração, implica colocar sobre bases concretas pesquisas sobre a constituição, a estrutura e a ação do Estado na sociedade contemporânea. Assim, as reflexões sobre gestão de políticas públicas, gestão tributária, governança, entre outras coisas, devem ser sustentadas em conceitos que se originam das especificidades sociais, econômicas, culturais, jurídicas e políticas. Tal é a quarta contribuição que este estudo pretende trazer para a área.

Em quinto lugar, rediscutir um tema que é polissêmico quando se restringe a compreender o conceito de burocracia é um desafio que precisa ser permanentemente enfrentado para evitar que a burocracia seja mais um conceito que se torna senso comum no mundo acadêmico. Considerando que Tragtenberg e Prestes Motta são referências importantes em vários campos de estudos, a análise de suas contribuições, apresentando conformidades e diferenças em relação à burocracia, reascende o debate em torno de um tema fundamental que parece ter desaparecido das discussões acadêmicas recentes ainda que não tenha 
desaparecido da realidade organizacional. Retomar este debate a partir de dois autores de referência no Brasil no estudo deste tema é a quinta contribuição que este estudo pretende oferecer.

Para tanto, este estudo tem como objeto de análise as principais obras de Maurício Tragtenberg e Fernando Cláudio Prestes Motta, conforme resumido no Quadro 1, adiante. mento de um fenômeno social implica a extração do conteúdo simbólico da ação que o configura" (FARIA, 1983 , p. 23). Para explicar os processos particulares "Weber propõe a utilização dos chamados 'tipos ideais', que representam o primeiro nível de generalização de conceitos abstratos" (FARIA, 1983, p. 23). É com base neste método que Weber analisa o fenômeno da burocracia (WEBER, 1974; 1982; 1989).

\section{Quadro 1 - Principais textos utilizados no estudo}

\begin{tabular}{l|l}
\multicolumn{1}{c|}{ AUTOR } & \multicolumn{1}{c}{ TRABALHOS } \\
\hline Maurício Tragtenberg & $\begin{array}{l}\text { Burocracia e ideologia (TRAGTENBERG, 1974), Reflexões sobre o socialismo (TRAGTENBERG, 1986), Admi- } \\
\text { nistração, poder e ideologia (TRAGTENBERG, 1989), Sobre educação, política e sindicalismo } \\
\text { (TRAGTENBERG, 2004) e vários textos publicados em jornais. }\end{array}$ \\
\hline Fernando C. Prestes Motta & $\begin{array}{l}\text { geral da administração: uma introdução (PRESTES MOTTA, 1989), Organização e poder: empresa, estado } \\
\text { e escola (PRESTES MOTTA, 1990), Teoria das organizações: evolução e crítica (PRESTES MOTTA, 2001), } \\
\text { Introdução à organização burocrática (PRESTES MOTTA e BRESSER PEREIRA, 1980) e Teoria geral da }\end{array}$ \\
& Administração (PRESTES MOTTA e VASCONCELOS, 2004).
\end{tabular}

Todo estudo teórico exige método e procedimento, diferente de simples revisão teórica. Este estudo tangencia a história dos conceitos, alicerçado nos pressupostos de que: a trajetória intelectual dos autores contribui para o entendimento do conceito estudado; a ordem das produções dos autores é importante para a compreensão do conceito em análise; as epistemologias estruturantes do conceito apresentam importante relevância para se compreender seu significado; o estudo de todo conceito deve ser compreendido em seu espaço e seu tempo histórico; todo conceito tem sua dimensão semântica, ideológica e cultural; determinados questionamentos (Para quem o autor escreve? Baseado em que perspectiva teórica? Qual o posicionamento político do autor? De onde escreve? Quais são seus interesses?) são importantes para se compreender o desenvolvimento teórico do conceito.

\section{A BUROCRACIA SEGUNDO WEBER: PONTO DE PARTIDA DE TRAGTENBERG E PRESTES MOTTA}

Para Max Weber o "objeto da sociologia é a captação de sentido da ação humana, à medida que o conheci-
Weber analisa o processo de racionalização da sociedade na passagem da Idade Média para a Idade Moderna. O desencantamento do mundo, baseado no cálculo utilitário de consequências, substitui a mediação das relações sociais que antes estavam baseadas na tradição e no carisma. Uma racionalidade instrumental-legal se institui e modifica as relações na sociedade, fazendo com que a burocracia moderna se consolide como razão materializada desse processo histórico. Para chegar a essa compreensão, Max Weber analisou a burocracia do sistema de produção asiático e de outras sociedades deslocadas e dentro de seu tempo histórico. Entretanto, as características da burocracia moderna são próprias de uma racionalização estabelecida dentro do sistema capitalista de produção. Dessa forma, mesmo em Weber, a burocracia, quando analisada isoladamente, ou seja, como fenômeno atemporal, perde sentido, pois é por meio da racionalidade oriunda de um modo de produção específico que uma estrutura se ergue e se instaura. A vantagem técnica da organização burocrática no capitalismo é a superioridade puramente técnica sobre qualquer outra forma de organização. O mecanismo burocrático plenamente desenvolvido compara-se às outras organizações exatamente da mesma forma pela qual a máquina se compara aos modos não mecânicos de produção (WEBER, 1982, p. 249). 
Segundo Weber (1982, p. 229), a burocracia moderna funciona sob formas específicas. A burocracia está sob a regência de áreas de jurisdição fixas e oficiais, ordenadas por leis e normas administrativas. Ela estabelece relações de autoridade, delimitada por normas relativas aos meios de coerção e de consenso. Uma relação hierárquica se estabelece, definindo postos e níveis de autoridades, além de um sistema de mando e subordinação com gerência das atividades e tarefas delegadas por autoridade. Nesse contexto, a administração é formalizada por meio de documentos, que acabam por regular a conduta e as atividades das pessoas. O treinamento é fundamental nas burocracias especializadas devido às especificações das atividades e dos trabalhos. O treinamento especializado volta-se para generalizar o cargo e transformá-lo em profissão. As atividades e tarefas de um trabalho transformado em profissão, que podem ser apreendidas por qualquer trabalhador, são descritas e delimitadas pela criação de cargos mais ou menos estáveis. A ocupação de um cargo configura uma profissão de ordem impessoal e transitória. A posição pessoal de um funcionário é desfrutada e estimada em um contexto social específico, sempre em comparação aos demais funcionários e em relação à estrutura social. Os funcionários recebem salários (compensação pecuniária) regulares, criando-se certa segurança social em troca das atividades exercidas por ele. Esse salário é definido pela tarefa realizada, por suas particularidades e pela posição hierárquica do funcionário. A burocracia cria uma carreira dentro da ordem hierárquica estabelecida.

Para Weber (1974), o cumprimento dos objetivos efetiva-se por tarefas definidas, que devem ser calculadas e precisam ser realizadas independentemente das características das pessoas, ou seja, o cumprimento das mesmas deve se revestir de impessoalidade.

A estrutura burocrática concentra os meios materiais de administração nas mãos das elites detentoras do capital, mediante o desenvolvimento das grandes empresas capitalistas. Quando a burocracia se estabelece plenamente, ela se situa entre as estruturas sociais mais difíceis de serem destruídas, configurando-se um meio de transformar ação comum em ação societária, racionalmente ordenada. Dessa forma, constitui um instrumento de poder, de dominação, pois, ninguém pode ser superior à estrutura burocrática de uma sociedade.

Outra característica descrita por Weber (1982, p. 269) em relação à burocracia é que ela potencializa os segredos, conhecimentos e intenções. Na administração burocrática, tende a ser uma estrutura organizada de pequenas sessões secretas, na medida em que oculta conhecimentos e ações. Dessa forma, o poder do perito, ou funcionário especializado, é aquilatado e, por esse motivo, a qualificação como forma de especialização crescente resulta muito valorizada. A burocracia, portanto, "tem um caráter 'racional': regras, meios, fins e objetivos dominam sua posição" (WEBER, 1982, p. 282). Assim, para Weber "a burocracia descansa na aceitação da validez de algumas leis não excludentes [em que o] processo administrativo, dentro dos limites especificados nas ordenações significa a busca racional de interesses, de forma que as atividades destinadas a atingir os objetivos organizacionais apresentam-se aos executores como 'deveres oficiais"” (FARIA, 1983, p. 27). Para Weber, portanto, a burocracia é um eficiente instrumento de poder. Esta concepção de burocracia enquanto poder e dominação vai fazer parte constitutiva, ainda que não exclusiva, das análises de Tragtenberg e Prestes Motta.

\section{A PERSPECTIVA DA BUROCRACIA EM TRAGTENBERG}

A concepção de Tragtenberg em relação à burocracia é essencialmente weberiana. Assim como Marx, Weber está entre os autores mais estudados em sociologia. Particularmente em relação a Weber, existem diversas leituras e interpretações. "Assim, temos o Weber de Talcott Parsons, quase um 'sociopsicólogo'; o Weber positivista de Adorno/Horkheimer, um apologista do status quo; o Weber fenomenológico de Alfred Schutz; e o Weber preso à ilusão objetivista de Lucien Goldmann e Michael Löwy" (LAZARTE, 1996, p. 27).

Maurício Tragtenberg, sobretudo pela sua fluência com a língua alemã, que lhe possibilita inclusive a tradução dos textos de Weber para o português, pôde fazer uma análise acurada das ideias originais de Weber. Uma compreensão importante em relação a Weber, como intelectual, é "pensar e refletir criticamente com Weber e não polemizar contra Weber, sem subterfúgios, escamoteação dos problemas centrais, penetrando na reflexão efetiva para superar, isto é, absorver a contribuição de Weber e excedê-la" (TRAGTENBERG, 1974, p. 156). Muitas divergências ocorridas em relação às ideias de Weber se efetivaram porque vários acadêmicos e intelectuais, municiados dos seus pressupostos teóricos, não compreenderam o 
contexto histórico em que a teoria da burocracia foi escrita. Tragtenberg, nessa situação, convida os estudiosos interessados na compreensão da teoria weberiana para "superar em Weber as limitações do tempo e contexto social em que se situa a sua obra; discuti-la sem compromissos ideológicos que impliquem o sacrifício do intelecto com o respeito que uma obra do porte da que ele nos legou implica" (TRAGTENBERG, 1974, p. 157).

Sem desconsiderar o rigor epistemológico, Weber contribui para a compreensão do processo de racionalização, em que a sociedade tradicional, baseada nas crenças, valores e em uma economia atrelada ao período da Idade Média, transforma-se em uma sociedade baseada nas relações em que os fins são mais importantes que os meios e em que o desencantamento do mundo é uma realidade permanente. A obra de Weber segue a tradição da filosofia alemã, e sua teoria da burocracia ocorre em um período de formação econômico-social do capitalismo. Antes dele, Hegel já procurara entender a burocracia por outras categorias de análise. Ambos, Weber e Hegel, procuraram compreender a burocracia prussiana no contexto do processo de racionalização do mundo capitalista, por vias diferentes. "Diferentemente das burocracias patrimoniais do Egito, da China, de Roma e de Bizâncio, a burocracia capitalista na Europa ocidental fundara-se na economia capitalista, transpondo a área administrativa à crescente divisão de trabalho e à racionalização" (TRAGTENBERG, 1974, p. 93).

Tragtenberg tem ciência de que a burocracia estudada por Weber é um processo marcado por características determinadas por um período histórico em que o capitalismo é a forma econômica dominante. A análise de Tragtenberg é, antes de tudo, uma avaliação de caráter histórico, não se podendo negar, em razão disso, que o fundamento epistemológico que acompanha Tragtenberg seja o materialismo histórico. É com base no marxismo que Tragtenberg dialoga com Weber, na medida em que parte do fato histórico de que a burocracia é consequência de uma forma específica de racionalização, originária da divisão do trabalho no contexto do capitalismo. Marcuse (1998), que na introdução de um estudo de Weber (1973) considera que as ideias weberianas comprometidas com o liberalismo burguês chocam-se com sua pretendida neutralidade axiológica, chegou com propriedade à conclusão do caráter histórico da burocracia estudando o processo de burocratização na sociedade industrial.

Conforme Faria (2009), Tragtenberg busca em Hegel a concepção inicial da relação entre Estado e burocracia, o que lhe permite vislumbrar as características do modo de produção asiático na perspectiva do poder político. A base de sua argumentação criará as condições analíticas para a crítica da burocracia nos regimes de Estado, e, ao fazer tal crítica, Tragtenberg antecipa o que se tornará a prática dominante das empresas capitalistas contemporâneas no que se refere ao controle sobre a organização e o processo de trabalho. Para Tragtenberg (1974, p. 22), "a administração, enquanto organização formal burocrática, realiza-se plenamente no Estado", razão pela qual, "o segredo da gênese e estrutura da teoria geral da administração, enquanto modelo explicativo dos quadros da empresa capitalista, deve ser procurado onde certamente seu desenvolvimento mais pujante se dá: no âmbito de Estado". A teoria administrativa fornece ao capitalismo industrial modelos de transição do liberalismo para o capitalismo monopolista e a "emergência da burocracia como poder funcional e político".

Apesar de os estudos de Weber serem considerados o ponto de partida sobre o estudo da burocracia, este tema aparece direta (MICHELS, 1968) ou indiretamente (PROUDHON, 2007) em estudos clássicos no campo da política ou da filosofia. No campo da análise das organizações, diversos são os direcionamentos adotados sobre essa temática, que é amplamente estudada sob múltiplos recortes teóricos e perspectivas epistemológicas. Entre estes se destacam dois autores fundamentais na compreensão da burocracia: Mauricio Tragtenberg e Fernando Cláudio Prestes Motta. A partir deles, outros pesquisadores relacionados aos estudos críticos na administração ou mesmo de outras abordagens teóricas e epistemológicas foram e são influenciados por suas análises sobre a burocracia. É exatamente pela importância dos estudos de Tragtenberg e Prestes Motta que a presente análise se justifica. O tema da burocracia, além disso, pode ser considerado como um pressuposto elementar para a existência da teoria das organizações, especialmente a partir da perspectiva behaviorista (FARIA, 2004). É a partir da burocracia enquanto forma de racionalização que as organizações complexas modernas (ETZIONI, 1973; 1974) se efetivaram como objetos de análise. $\mathrm{Na}$ atualidade, conforme questiona Tragtenberg, é preciso entender como é possível se defender do avanço implacável da burocracia. "Esta é a preocupação central de Weber que não se esquece de advertir que a burocracia é uma máquina de difícil destruição" (TRAGTENBERG, 1974, p. 144). Burocracia é o oposto de autonomia, tanto individual como coletiva. O 
próprio pensamento da atualidade encontra-se refém da burocratização. No interior das organizações, os trabalhadores - do operário ao executivo - são condicionados pelas determinações de que a burocracia (vista como sedimentação da racionalização oriunda da divisão do trabalho) impõe. Para Tragtenberg, a burocracia materializa a face perversa do capital; resulta num problema real com origem na expansão do sistema de capital. Nos seus estudos, a proposta sempre foi criar mecanismos de defesa ante os nefastos efeitos da burocracia.

$\mathrm{Na}$ interpretação de Tragtenberg (1974, p. 139), em Weber a burocracia é "um tipo de poder. Burocracia é igual à organização". Tragtenberg compreende que a complexidade crescente das organizações no sistema capitalista faz com que elas adotem, na mesma proporção, uma estrutura racional legal caracterizada pela impessoalidade para garantir a reprodução da própria organização. Além disso, a burocracia é entendida como um sistema racional construído da divisão do trabalho, que tem, como princípio, os fins.

A especialização crescente deixa a burocracia organizacional cada vez mais forte. Os gestores isentam-se de responsabilidades pela regra da impessoalidade, do formalismo ou do discurso de profissionalismo. A capacidade do indivíduo dá lugar à profissão e à própria autoridade intrínseca quanto ao cargo com suas respectivas responsabilidades. A dinâmica da constituição da burocracia dar-se-á, portanto, com base na divisão do trabalho, que faz com que o trabalhador especializado seja percebido, contraditoriamente, de duas formas: o especialista passa a concentrar conhecimento específico, ao mesmo tempo que destitui dos demais trabalhadores o poder de eles agirem, por falta, justamente, de conhecimentos específicos. Por outro lado, o trabalhador especializado desumaniza-se cada vez mais, pois o conhecimento, a habilidade ou a competência específica interessam à organização e não ao indivíduo. Assim, a organização, que não deve depender de ninguém, articula-se para criar substitutos para o especialista. Criam-se e incentivam-se aparatos ideológicos e um conjunto de tecnologias e técnicas, para envolver o trabalhador de forma sutil e silenciosa. Explicitam-se: tecnologia da informação, sistemas de controles gerenciais, manuais de gestão, protocolos de qualidade, normas, regras, hierarquias, assim como técnicas de gestão colaborativas e participativas, em que os exemplos mais recentes e eficientes são o kaizen, utilizado em ampla escala no sistema
Toyota de produção, o os grupos semiautônomos, utilizados por empresas suecas (FARIA, 2004).

Tragtenberg via em Weber a separação entre $\mathrm{O}$ econômico e o político. Em um aprofundamento sobre a separação entre as esferas econômicas e políticas, Tragtenberg destaca que "a dualidade da realidade alemã é vivida por Weber no seu labor sociológico: a separação das esferas do político e do econômico; a dialética das formas de dominação oscilando entre o carisma e a burocracia." (TRAGTENBERG, 1974, p. 107). As contradições existentes na própria realidade vivenciada por Weber configuram-se elementos importantes na sua construção teórica. Conforme salienta Richard Sennet (2007), a teoria da burocracia é influenciada pela burocracia militar, cuja rigidez organizacional se generaliza no âmbito da sociedade.

Para Weber, essa generalização significa a tendência à crescente complexidade das organizações, surgindo a burocracia como uma forma organizada decorrente da racionalização consolidada pela formação dos grandes Estados nacionais. Os interesses particulares são dispersos pela generalidade imaginária do coletivo, e o Estado, visto como ente que representa os interesses da maioria, na realidade consolida os interesses particulares. Assim, "as finalidades do Estado são as da burocracia e as finalidades desta se transformam em finalidades do Estado" (TRAGTENBERG, 1974, p. 24).

A legião de trabalhadores que formam a máquina burocrática do Estado exerce, no limite, os interesses de uma parte da elite dominante, realizando a tarefa de mediação do capital com os interesses do coletivo, por meio de participações específicas no processo de racionalização, inclusive do trabalho.

\footnotetext{
Quando o Estado é mencionado como organizador do processo de trabalho, não significa que existe uma primazia do econômico na determinação de sua função. O Estado exerce sua função global de coesão através, igualmente, de seus sistemas jurídicos (regras que organizam e disciplinam as trocas capitalistas), políticos (a manutenção de ordem em casos de conflitos) e ideológicos (o papel no ensino, nas propagandas institucionalizadas etc.). As funções particulares, mencionadas, correspondem sempre a interesses políticos das classes dominantes. (FARIA, 2004, p. 101).
}

Tragtenberg (1974, p. 132), em uma leitura de Weber, percebe que, na concepção do sociólogo alemão, a crescente socialização (aqui definida como estatiza- 
ção da economia) dos meios de produção na posse de um Estado proletário implica, necessariamente, aumento da burocratização. A ditadura do proletariado seria, inevitavelmente, transformada em ditadura do burocrata, do funcionário do Estado.

Diante dessa análise, a eliminação do capitalismo não seria suficiente para resolver o problema da burocratização, mesmo com o Estado sendo dirigido pelos operários (TRAGTENBERG, 1974, p. 142).

Resta evidente que a superação da burocracia não pode ocorrer apenas por meio da consciência política dos trabalhadores. A própria estrutura econômica na sua unidade elementar, que é o modo de produção, consolida essa burocracia como forma específica de organização da produção e, consequentemente, da sociedade em geral. Na fase atual de desenvolvimento das forças produtivas, não há como negar a existência de uma forma de burocracia que estrutura $o$ aparato administrativo das unidades produtivas, uma vez que ela apenas consolida uma forma específica de produção. Todavia, quando a "burocracia participa da apropriação da mais-valia, participa do sistema de dominação. [...] Em suma, ela une a sociedade civil ao Estado" (TRAGTENBERG, 1974, p. 190).

Tragtenberg recorre a Hegel (2000) exatamente para analisar a burocracia como poder administrativo e político, a partir do conceito deste de que o Estado é a organização (burocracia pública) acabada, a síntese do substancial e do particular, a integração dos interesses individuais e particulares. Assim, o Estado é visto em sua representação instrumental, pois a burocracia é o formalismo de um conteúdo que se encontra fora dela, que é a corporação privada. É como instrumento das classes dominantes que a burocracia tem efeitos de permanência com relativo nível de autonomia. Estado e sociedade civil se encontram separados na visão hegeliana, pois o primeiro contém o interesse universal e a segunda o interesse particular, mas é no interesse geral que reside a conservação dos interesses particulares.

Tragtenberg (1974, p. 23) reconhece que a teoria de Hegel é sustentada em "um formalismo político que encobre a realidade que ele desnatura, reduzindo arbitrariamente a oposição e traindo o real". Por esse motivo, buscar em Hegel uma base analítica não é simplesmente incorporar uma concepção hegeliana. O recurso a Hegel é para afirmar sua convicção de que as finalidades do Estado são aquelas da burocracia e as desta são as do Estado, de forma que a burocracia se fundamenta na separação entre os interesses uni- versais e particulares como elemento de mediação. Nesse sentido, a burocracia, nos regimes de Estado, constitui-se para Tragtenberg como classe dominante, pois detém os meios de produção e, nessa medida, possui o poder de exploração, cumprindo funções de organização do monopólio do poder político. Desse modo, Tragtenberg (1974, p. 28) encontrará em Hegel "as determinações conceituais que permitem a análise da burocracia do Estado, da burocracia enquanto poder político que antecede em séculos a emergência da burocracia determinada pelas condições técnicas da empresa capitalista, oriunda da Revolução Industrial".

Ao examinar o modo de produção asiático, Tragtenberg afirma que, neste, o Estado extrai sob a forma de impostos a mais-valia da economia de subsistência das aldeias. Sua concepção, nesse sentido, é muito particular. Não no que se refere ao fato de o Estado apropriar-se da mais-valia na forma de impostos, mas de considerar a economia de subsistência das aldeias uma forma de organização do trabalho que gera mais valor. Para sustentar esse argumento, Tragtenberg entende que "o povo cria pelo trabalho" e sua "remuneração" é o conjunto dos bens de consumo. A mais-valia decorre, dessa forma, da renda da terra, da qual o Estado se apropria para a realização de obras e para a manutenção da burocracia. As forças produtivas desse modo de produção são mais intensivas de trabalho humano do que de meios de produção, o que "pressupõe uma superexploração da força de trabalho que compensa a subutilização das possibilidades tecnológicas" (TRAGTENBERG, 1977, p. 29). Em que medida, neste ponto, se encontra o trabalho objetificado e alienado?

Tragtenberg trata dessa questão ao abordar a filosofia do conflito social em Marx, na qual o trabalho aparece como fator de mediação que enriquece o mundo dos objetos e empobrece a vida interior do trabalhador na medida em que este não é dono de si mesmo. O resultado do trabalho é estranho ao trabalhador e surge como um poder independente dele (TRAGTENBERG, 1974, p. 69). Essa análise permite compreender as relações de trabalho para além da burocracia. Para tanto, é necessário entender que em Hegel (2001) a história do homem é a história do espirito absoluto, uma consciência que se revela de forma progressiva por meio de uma série de contradições dialéticas em direção a um autoconhecimento cada vez maior, pois a consciência ilimitada é o estado supremo em que o espírito se encontra com o mundo ético (SWINGEWOOD, 1978, p. 107). 
Sendo a alienação um processo no qual a objetificação opera no homem como um poder opressivo, a concepção de Tragtenberg sobre o domínio da burocracia como poder político no regime que ele chama de "capitalismo de estado", essa "combinação inédita de iniciativa individual no plano econômico com a economia de Estado" é uma concepção da burocracia como uma elite alienante. De fato, o capitalismo de Estado é para Tragtenberg (1974, p. 40-41) "o processo de modernização levado a afeito por uma elite industrializante sob a direção de um partido único". O monopólio do poder por esse partido, portanto, assegura a seleção da elite dirigente em que a ascensão na escala partidária corresponde à promoção na burocracia estatal. "Esta burocracia possui o Estado como propriedade privada, dirigindo coletivamente os meios de produção."

A partir daí, Tragtenberg critica o modelo soviético de dominação burocrática bem como o coletivismo burocrático da Iugoslávia aliado ao monopólio do poder do partido único, no qual o líder central é o único animador do sistema e o único possuidor da crítica. "Os órgãos de autogestão representam a burocracia dominante", pois a burocracia "não é só o elemento oriundo das necessidades funcionais da técnica, mas é acima de tudo poder político total" (TRAGTENBERG, 1974, p. 44). Tragtenberg, recorrendo a Mannheim (1976), percebe que esse processo tem implicações também no plano das ideias ao valorizar, como elementos de reforço do sistema: (i) em primeiro plano, o conhecimento político doutrinário e restringir o conhecimento filosófico à interpretação dos donos do poder, fazendo emergir o líder carismático por meio da dogmatização; (ii) em segundo plano, o conhecimento científico: (iii) em terceiro plano, o conhecimento técnico. É aqui que o poder político da burocracia se constitui também como ideologia.

Contudo, não foi somente no âmbito da discussão acadêmica que Tragtenberg explanou sua opinião em relação à burocracia, pois em outros locais de discussão também manifestou suas ideias a respeito sem abrir mão de sua coerência de raciocínio e militância política. Avesso a qualquer forma de burocratização que impedisse a autonomia dos indivíduos, caracteriza-se um dos pioneiros na crítica ao regime autoritário com que o socialismo tentou se estabelecer no leste europeu. Com efeito, para Tragtenberg, o que ocorre, na realidade, "é que com o nome de economia socialista existe uma economia de Estado nas mãos de uma burocracia dominante, que exerce o poder em nome do trabalhador" (TRAGTENBERG, 1981a).
A clareza da análise de Tragtenberg demonstra domínio em relação ao fenômeno da burocratização. A burocracia instalada nos países chamados socialistas ocorre igualmente em outros Estados declaradamente liberais, porém com uma máscara diferente. Tragtenberg, a escrever sobre o leste europeu, afirma que "sob Stálin, o regime do leste europeu reproduziu o modelo russo: economia de Estado regida por uma burocracia que gozava de imunidades e privilégios defendidos por um Estado policial, onde a liberdade era vista como "preconceito burguês'" (TRAGTENBERG, 1990).

Mesmo os partidos políticos são incorporados pela burocratização e "o problema mais sério do partido (...), após escalar o poder, [é saber] quem o tira de lá. (...) As diferenças entre os partidos brasileiros são de rótulo. Eles se constituem nos viveiros de uma nova burocracia tecnocrática que, legitimada pelo voto popular, melhor poderá explorá-lo e dominá-lo" (TRAGTENBERG, 1981b).

O Estado, de certa forma, estrutura-se para manter a ordem vigente, além de criar normas, regras, hierarquias e organizações de forma muito semelhante às empresas da iniciativa privada. As diferenças apresentam-se, nessas situações, apenas para garantir a reprodução do sistema e o equilíbrio estrutural para que o capital avance com o mínimo de dificuldade possível. Tragtenberg não poupou esforços para compreender o fenômeno da burocracia nos diversos contextos sociais. Em relação à Polônia, por exemplo, alertou sobre o poder degenerativo da burocracia ante os avanços do proletariado na construção do regime socialista. Sobre as ditaduras, não deixou de mencionar a burocracia cubana e romena bem antes das mudanças que ocorreram.

Para Tragtenberg, o Estado, como representante e legitimador da burocracia, tem papel central na consolidação de uma sociedade organizada em função de crescente processo da ação racional-legal, que legitima os interesses do capital. Para Tragtenberg "a máquina do Estado funda seu poder sobre o controle de todos a partir do centro: ela funciona na monarquia absoluta que estatiza pouco a pouco todos os aspectos da vida, todos os detalhes do comportamento social, econômico, político, sexual e afetivo" (TRAGTENBERG, 1989, p. 110).

A concepção do Estado como meio de controle e aparelho repressor se faz evidente em Tragtenberg. Para ele, qualquer forma de Estado representa um tipo de burocracia e, dessa forma, nada mais representa que uma sociedade que sofre um processo de desencantamento do mundo, ou seja, uma manifesta- 
ção evidente e clara da ação racional-legal de como os meios de produção se organizam e se constituem. Para Tragtenberg, "[...] as lutas sociais podem tender à burocratização e à perda de suas finalidades iniciais, mas há sempre alguém - a classe trabalhadora - que reage a isso criando suas entidades igualitárias e novas relações sociais antagônicas à burocratização" (ACCIOLY, 2001, p. 80). Tragtenberg considera o processo de burocratização um fenômeno social em consequência, também, do grau de complexidade das forças produtivas em uma sociedade que passa a quantificar-se em todas as dimensões da vida social, inclusive da educação.

Tragtenberg era um crítico intransigente de toda a forma de autoridade, de poder, de burocracia e de dominação. Sua vinculação não dogmática ao anarquismo não era apenas uma questão política, porque Tragtenberg não separava a ação do pensamento. Tragtenberg analisava a realidade de um ponto de vista marxista, mas não se deixou dogmatizar por isso. Vinculava-se ao anarquismo, mas não se deixava encantar por suas utopias. Suas escolhas eram escolhas teóricas, sem dúvida, mas eram também políticas e, principalmente, assumiam uma posição epistemológica, porque sua forma de produzir conhecimento, sua forma de transmiti-lo mediante uma pedagogia libertária, condicionaram sua interpretação do real.

A perspectiva de Tragtenberg (1977, p. 16) é a de uma análise com fundamento na sociologia do conhecimento, do "estudo da causação social das teorias da administração como ideológicas". Tal análise é categórica, baseada em textos e se opera em três níveis: (i) lógico: como administração significa burocracia, Tragtenberg recorre a Hegel; (ii) histórico: sendo as teorias administrativas transitórias (ideológicas) porque refletem interesses econômico-sociais transitórios, Tragtenberg recorre à dialética; (iii) lógico-histórico: como as teorias administrativas, embora refletindo momento histórico-econômico específico, trazem em seu interior conhecimentos cumulativos, Tragtenberg recorre a Marx para examinar a autonomia relativa da produção teórica em relação às determinações econômico-sociais (FARIA, 2009, cap. 1).

\section{PERSPECTIVA DA BUROCRACIA EM PRESTES MOTTA}

Para adequar as contribuições de Prestes Motta aos propósitos deste trabalho, utilizam-se as suas prin- cipais análises (PRESTES MOTTA, 1981, 1982, 1989, 1990, 2001; PRESTES MOTTA e BRESSER-PEREIRA, 1980; PRESTES MOTTA E VASCONCELOS, 2004).

Em seu primeiro livro, de 1972 (PRESTES MOTTA, 1989), que se tornou leitura obrigatória nos cursos de graduação em administração, "a forma de tratamento da teoria da administração revela que, em todas as abordagens, o que se encontra são relações de dominação das mais variadas espécies, indicando como os diferentes enfoques reproduzem uma visão segundo a qual é da gerência o papel fundamental na coordenação das organizações. Tanto que Motta sugere que apenas uma autogestão seria capaz de propor estrutura de poder diferenciada" (FARIA, 2003, p. 164). Assim é que, ao tratar especificamente da teoria das organizações, Prestes Motta (2001) afirma que as teorias organizacional e administrativa devem ser analisadas como "ideologia do poder", pois ocultam o próprio poder e as contradições que lhes são inerentes, bem como a forma como a tecnoburocracia vê a organização, "base última de seu poder".

Prestes Motta, um estudioso das obras de Weber e de Marx, procurou esclarecer como a relação do sistema de produção capitalista com os elementos da infraestrutura pode formar a burocracia. A ligação advém de um processo de racionalização, provocada por condições específicas da produção. Prestes Motta (1981, p. 7) afirma que a "burocracia é uma estrutura social na qual a direção das atividades coletivas fica a cargo de um aparelho impessoal hierarquicamente organizado, que deve agir segundo critérios impessoais e métodos racionais".

A burocracia nasce das relações de produção, consolida-se no Estado como forma organizada de controle social e amplia-se com as organizações de modo geral. Assim, a sociedade moderna tornou-se uma "sociedade de organizações burocráticas submetidas a uma grande organização burocrática que é o Estado" (MOTTA, 1981, p. 8). Adotando-se as orientações de Weber e Marx, segundo Prestes Motta (1981, p. 8-9), a burocracia apresenta algumas características. Mantém-se um estado de segurança e conformismo em troca do trabalho assalariado de boa parte das pessoas. As pessoas participam de grandes organizações impessoais e a vida em comunidade perde sentido. O próprio trabalho perde significação intrínseca nas organizações burocráticas. As necessidades das pessoas são manipuladas por meio das relações entre produção e consumo, orientando a vida das pessoas. Com isso, o comportamento passa a ser disciplinado 
e caracterizado como irresponsabilidade social, caso o comportamento padrão não seja seguido.

$\mathrm{Na}$ esfera política, a participação das pessoas perde sentido, sobretudo, porque as pessoas não participam de fato das decisões relevantes. É fortalecida a aparência de que a democracia é efetivamente o regime político dominante. Isso ocorre por meio dos partidos políticos e sindicatos, vistos como organizações burocráticas que criam a falsa sensação de participação democrática nas decisões políticas da sociedade.

As análises de Prestes Motta em geral (1981, 1982, 1989, 1990) apresentam uma concepção marxista em relação à burocracia, porém, ao tratar deste tema na perspectiva weberiana, Prestes Motta adota uma posição na qual as categorias são construídas no plano abstrato arbitrário, o que não significa uma recusa à história. De fato, para chegar à afirmação sobre as características descritas anteriormente, Prestes Motta entende a burocracia de três formas: como poder, como controle e como alienação.

Assim, a burocracia como poder só pode ser compreendida "na medida em que analisamos a sua história" (PRESTES MOTTA, 1981, p. 12). O processo de burocratização no contexto do sistema de produção capitalista é um fenômeno universal e, como tal, é parte de um sistema antagônico próprio do sistema de capital. A burocracia é um instrumento da classe dominante que impõe sua ascendência sobre as demais classes. Essa dominação é feita pelas organizações (empresas, escola, partidos, sindicatos e outros) e pelo Estado, por meio do estabelecimento de um modo de vida específico, de acordo com os interesses do capital.

O "modo burocrático de pensar leva o homem ao vazio e à luta por pequenas posições na hierarquia social de prestígio e consumo" (PRESTES MOTTA, 1981, p. 13). Levando-se em consideração a história, outro fato importante é que a da burocracia é a história do afastamento entre trabalho manual e trabalho intelectual, cuja separação entre os que pensam e os que executam estabelece uma relação hierárquica bem definida, adequada aos interesses do capital. Para tanto, as operações no trabalho são isoladas em parcelas que, posteriormente, são aprimoradas, classificadas e agrupadas, obedecendo à lógica da separação entre concepção e execução. A partir disso, Prestes Motta considera que se cria uma nova lógica para o processo de qualificação dos trabalhadores, passando o trabalhador coletivo a desempenhar atividades sistematizadas, racionalizadas e previsíveis, cujo controle não detém mais. Dessa forma, uma nova cooperação é estabelecida de acordo com os interesses do capital.

Tudo isso ocorre por causa da eficiência, responsável por aumentar a produção da mais-valia e, consequentemente, de aumentar a taxa de lucro. Concentra, ainda, o "poder de decisão", já que o novo agrupamento retira da maioria tal poder por meio da expropriação do planejamento, da criatividade e do conhecimento amplo e integral.

Tudo isso se faz sob o comando das funções diretivas, que coordenam o processo. [...] É por essa razão que as técnicas de organização, que começam a ser necessárias com a divisão do trabalho, são técnicas capitalistas, que visam ao aumento da mais-valia. Racionalizar o trabalho significa aumentar a mais-valia relativa, isto é, a mais-valia que se obtém com a intensificação do trabalho (PRESTES MOTTA, 1981, p. 20-21).

A unidade de poder da burocracia é a organização, representada principalmente pela empresa capitalista. A integração dessa unidade é feita pelo Estado, que desempenha papel fundamental para manter a concentração de poder. Assim, a empresa burocrática pressupõe, para Prestes Motta, o Estado burocrático responsável por manter a ordem e o controle social. O Estado aparece dessa forma como uma organização burocrática fundamental, consolidando uma elite política normalmente associada à classe dominante e criando, além disso, um corpo de funcionários hierarquicamente organizados para se ocuparem da administração. Procura-se manter, com essa organização, a ordem interna, além de proteger o Estado constituído das ameaças externas. Essa organização estatal burocrática utiliza-se do seu poder disciplinador, de políticas que promovam consenso social e, também, o monopólio da violência, visando manter a própria burocracia.

Utilizando a categoria weberiana, Prestes Motta afirma que o poder do Estado e da burocracia em geral está associado principalmente a uma forma específica de dominação: a racional-legal. Estabelece-se uma acreditação em relação às leis e à ordem legal, cujos principais instrumentos de controle, dentro de uma estrutura social específica, se constituem nas próprias regras, que necessitam de caráter impessoal para serem aceitas pela coletividade.

Prestes Motta e Bresser-Pereira (1980), em um estudo específico sobre a organização burocrática, indicam que essa organização é o tipo de sistema social dominante nas sociedades modernas e, como tal, trata-se de uma estratégia de administração e de dominação. Na mesma linha argumentativa de Poulantzas 
(1977), Prestes Motta e Bresser-Pereira argumentam que a burocracia pode se constituir em um grupo ou uma classe social. Além disso, é também uma forma de poder que se estrutura por meio das organizações burocráticas. Nesse estudo de Prestes Motta e Bresser-Pereira (1980), o conceito central da abordagem de Prestes Motta é que a burocracia é dominação, é poder. Tal expressão explicita-se no prefácio de outro texto (PRESTES MOTTA, 1982), em que Prestes Motta afirma que "o autoritarismo é, por todas as razões, a essência do fenômeno burocrático", sendo a burocracia uma forma de dominação e a "dominação uma forma de poder" (FARIA, 2003, p. 164-165).

Outra característica da burocracia é que ela é controle. De acordo com Prestes Motta (1981, p. 33), "as organizações burocráticas estão veiculadas à estrutura social. Elas reproduzem uma estrutura social característica de uma formação social. Essa reprodução significa uma recriação ampliada das condições de produção em uma dada sociedade, em um dado sistema econômico". Como consequência, reproduzem-se também as classes sociais dessa mesma estrutura. Sem embargo, na organização do trabalho, a especialização das tarefas faz com que o trabalhador domine de forma insignificante o processo produtivo, permitindo ao capitalista controlar o produto final. Assim, o expediente de controle do produto passa a ser do capitalista, e o trabalhador vende sua força de trabalho em troca de sua autonomia. A hierarquia burocrática nasce, por conseguinte, na fábrica, contexto em que "hierarquia e divisão parcelar do trabalho se conjugam como molas propulsoras de uma forma de produção e reprodução do capital" (PRESTES MOTTA, 1981, p. 37).

A hierarquia exerce significativo papel na instituição da burocracia como controle, estabelecendo uma relação de vigilância e de disciplinamento essencial para garantir a submissão do trabalhador, além de outro elemento importante: o salário. "Como os salários não estão relacionados com o valor que produzem, mas sim com a reprodução de sua subsistência, estão garantidas as condições para a reprodução do capital" (PRESTES MOTTA, 1981, p. 38).

O papel das organizações burocráticas não está associado apenas à produção de riqueza, de capital e das demais mercadorias e serviços, e, tampouco, à reprodução da mão de obra como força de trabalho ou garantia da sobrevivência do trabalhador por meio do salário. O papel das organizações burocráticas constitui-se em garantidor do controle social por meio do estabelecimento das relações de poder, que sempre ocorrem entre desiguais. As organizações burocráticas servem de unidades de dominação, sendo, igualmente, responsáveis pela inculcação ideológica, pela adoção da submissão, pelos comportamentos controlados e socialmente aceitos, todos entendidos como naturais. Assim, a organização burocrática configura-se numa estrutura de controle e poder.

Importa perceber "que, enquanto estruturas de dominação, as organizações burocráticas contêm em si um conflito latente, e para abafá-lo todas as instâncias são manipuladas. Isso quer dizer que há mecanismos econômicos, políticos, ideológicos e psicológicos utilizados para a neutralização do conflito". (PRESTES MOTTA, 1981, p. 48) As organizações burocráticas, destarte, procuram garantir o controle social, o monitoramento dos comportamentos, as padronizações e o consenso.

A terceira característica apresentada por Motta incide na burocracia como alienação. A dominação se apresenta como um "estado de coisas' no qual as ações dos dominados aparecem como se estes houvessem adotado como seu o conteúdo da vontade manifesta do dominante" (PRESTES MOTTA, 1981, p. 59). De acordo com Mészáros (2006) Marx apresenta a mais conhecida teorização sobre a alienação, que não parte da burocracia, mas do trabalho. A teoria da alienação do trabalho apresenta a contradição fundamental da produção capitalista de mercadorias, no sentido de que o trabalhador torna-se mais pobre na medida em que produz mais riqueza; torna-se mercadoria tão mais insignificante quanto mais riqueza produz. Dessa forma, enquanto cria valor no mundo das coisas, o mundo da vida dos homens aumenta em razão direta de sua depreciação.

O trabalhador depara-se com o produto como um objeto estranho, com o qual não se identifica, uma vez que a apropriação do objeto é feita pelo capital. A alienação do trabalhador quanto ao produto de seu trabalho implica, também, a alienação em relação à natureza, por meio da qual ele garante os meios de sua subsistência física. Trabalhar o conceito de alienação no interior da burocracia significa configurar a alienação como um elemento da superestrutura que garante a separação entre produtor e produto. No âmbito da teoria da gestão do processo de trabalho, significa intensificar a separação entre os que pensam e os que executam, fator condicionante na relação de posse do produtor e do produto.

"A burocracia implica [também] que os indivíduos não se possam inserir na sociedade de acordo com suas necessidades e seu bem-estar pessoal. Daí a 
relação decisiva entre burocracia e alienação. Nessa ordem de ideias, a alienação é tão necessária quanto o for a burocracia, e não são poucos aqueles que nos afirmam que esta última é um aspecto imutável da tecnologia industrial". (PRESTES MOTTA, 1981, p. 76). A burocracia garante a separação entre produtor e produto, da mesma forma que garante a separação entre homem e natureza por meio do afastamento físico, psíquico e social.

Para compreender criticamente a análise de Prestes Motta, dois conceitos precisam ser destacados: (i) alienação enquanto um processo no qual o homem se torna cada vez mais estranho no mundo criado pelo seu trabalho e (ii) objetificação enquanto forma de o homem exteriorizar-se na natureza e na sociedade pelo seu trabalho, um processo em que este se torna um objeto para os outros na estrutura das relações sociais, construída com base nas relações de produção. Marx e Engels (2007) criticam Hegel por tornar iguais dois conceitos diferentes. A alienação, para Marx e Engels, ocorre quando o homem objetificado encontra sua atividade operando nele como um poder estranho, opressivo, externo. No capitalismo a objetificação implica alienação, pois o capitalismo, ao dominar completamente o trabalho humano, o aliena totalmente. Ao contrário do que defendia Marcuse (1982), a teoria da alienação em Marx não é uma teoria do poder total. O poder sempre se defronta com outros poderes, pois para ser poder é preciso que esteja em relação, em prática de classes (FARIA, 2004, v. 1). Tal poder total, como a coisificação plena da sociedade burguesa proposta por Marcuse, significaria uma forma de fatalismo insuperável, um mundo sem contradição e sem história, em que a emancipação seria impossível. O que Prestes Motta chama de alienação, portanto, do ponto de vista marxista, é objetificação.

Prestes Motta (1990, p. 133) apresenta o surgimento de uma nova categoria no sistema de capital, os tecnoburocratas, os quais atendem aos interesses do capital, pois exercem atribuições de gestores. Na tecnoburocracia, a tecnologia é incorporada na lógica da burocracia vigente, potencializando o controle das organizações sobre os indivíduos. Dessa forma, "o controle social concentra-se cada vez mais nas mãos da tecnoburocracia, tanto pública quanto privada" (PRESTES MOTTA, 1990, p. 135).

Nessa perspectiva, Prestes Motta considera que a burocracia exerce dominação pela sua superioridade técnica comparativamente a outras formas de racionalização do trabalho, tornando-se ainda tão mais forte quanto maior for a utilização da tecnologia como meio de controle. As análises de Prestes Motta relacionando a tecnoburocracia com o Estado, a escola e as organizações mostram a dialética do fortalecimento da burocracia na medida em que ela está subsumida à lógica do sistema de capital e de sua tendência a estabelecer suas formas específicas. Diante do exposto sobre o entendimento de burocracia nas perspectivas de Tragtenberg e de Prestes Motta, faz-se necessário compreender o que há de comum e de diferente entre elas. Primeiro, a burocracia e sua forma de gestão, a heterogestão, constituem forma de poder, e a autogestão, de não poder. Segundo, o conceito de poder com que Motta trabalha refere-se a uma radical separação, nos processos decisórios, entre dirigentes e dirigidos, cuja superação não depende da integração dessas categorias, mas da superação da divisão, que não se poderá realizar no interior de uma burocracia, mas unicamente com sua supressão. Por fim, Motta vai analisar o poder como forma de dominação de uma burocracia - uma heterogestão -, ou seja, como uma prática que separa artificialmente dirigentes de dirigidos. O poder é, assim, um processo de exclusão dos dirigidos dos mecanismos decisórios, ainda que sua inclusão não venha a significar sua liberdade, mas apenas um acordo civilizado, cujos termos não são garantia de permanência.

\section{BUROCRACIA COMO ORGANIZAÇÃO, PODER E CONTROLE: REFLEXÕES PROVISÓRIAS}

Examinando o percurso teórico de Prestes Motta e Tragtenberg, pode-se verificar que leituras diferenciadas sobre a concepção de burocracia são possíveis, como já havia sido observado por Paes de Paula (2002, 2008), por exemplo. Exatamente por existirem essas diferentes interpretações é que se torna importante resgatar o pensamento original desses autores.

Tragtenberg e Prestes Motta remetem suas análises, enquanto escrevem, para os trabalhadores, para administradores, educadores, sociólogos, enfim, para sujeitos que se vinculam a uma prática social centrada no trabalho. Além deles, seus escritos também influenciam os estudiosos - intelectuais e pesquisadores - das áreas de humanidades e de ciências sociais. Embora Prestes Motta tenha sido professor da área de Edu- 
cação na USP e da de Administração da FGV-EAESP, são os trabalhos de Tragtenberg que possuem maior penetração nas áreas de Educação, Gestão e Ciência Política, principalmente pela sua atuação como militante político. Prestes Motta não teve uma militância prática no campo político.

Essa é uma característica material que diferencia os trabalhos de Tragtenberg dos de Prestes Motta. Devido a sua participação ativa como intelectual e também por seu permanente contato com a classe trabalhadora em seus escritos em jornais populares, as obras de Tragtenberg apresentam conteúdos mais intensos de militância. Ainda que ambos se dirijam aos intelectuais e à área acadêmica, Tragtenberg tem de fato uma atuação mais intensa junto à classe trabalhadora, inclusive em sua formação acadêmica, como é o caso de Antonio Ozaí da Silva, trabalhador do ABC paulista que atualmente é professor doutor na Universidade Estadual de Maringá. As diferenças de práticas políticas se refletem nas análises teóricas.

Tendo em vista que Prestes Motta é um dos três discípulos citados por Tragtenberg (1991) na área de estudos organizacionais (ainda que este nunca tenha concordado em formar discípulos), o posicionamento político de Tragtenberg e Prestes Motta é de oposição ao capital em defesa do trabalho. A burocracia, para ambos, tem como finalidade política a instituição de um aparelho de dominação com base em uma racionalidade que separa os que pensam dos que executam, consequência elementar da divisão técnica e social do trabalho. O posicionamento político de Tragtenberg, com relação a essa temática, sempre foi publicamente mais explícito porque seus escritos nos jornais No Batente, Folha de S.Paulo e Notícias Populares, por exemplo, tinham como objetivo formar o pensamento crítico entre os trabalhadores, enquanto Prestes Motta dirigiu suas publicações exclusivamente para a área acadêmica.

Outro fato importante é que ambos elegeram o materialismo histórico como uma dimensão epistemológica relevante, notadamente quando analisam a questão da centralidade do trabalho. Assim, mesmo quando suas análises se referem à burocracia, no sentido weberiano, é a categoria trabalho que permanece como orientadora de seus estudos. Pode-se especular que esse fato ocorra porque Prestes Motta adota os estudos sobre a burocracia de Tragtenberg como ponto de partida para suas próprias análises sobre o fenômeno, ou seja, a burocracia é concebida por ambos como uma superestrutura originada das relações materiais e sociais que se estabelecem na produção.
Dessa forma, a burocracia configura-se uma forma específica de racionalização que tem como sustentação o que acontece no âmbito da produção, especialmente na divisão técnica e social do trabalho.

Tragtenberg busca compreender como se dá a construção histórica da burocracia tendo por referência as análises de Weber, a quem via como pensador crítico da burocracia. Por isso, suas críticas à tendência burocratizante da modernidade incorporam o mesmo tipo de preocupação que Weber. Prestes Motta procura estudar os efeitos da burocracia sobre as relações sociais e como ela se consolida na modernidade sob a égide do sistema capitalista de produção.

A diferenças das trajetórias intelectuais e políticas entre Tragtenberg e Prestes Motta é outro fator importante. Tragtenberg teve uma formação autodidata, diferentemente da de Prestes Motta. As origens pessoais e o percurso de ambos foram distintos. Todavia, a aproximação com a teoria marxista e anarquista é um ponto de convergência que aproxima as análises de ambos do ponto de vista político. Contudo, ainda que Prestes Motta seja um seguidor das análises de Tragtenberg, isso não o impediu de construir uma obra diferenciada e original, especialmente no que se refere à sua aproximação com a psicossociologia, à psicodinâmica do trabalho e aos temas da cultura.

Suas trajetórias são marcadas por problemas enfrentados no interior das grandes estruturas burocráticas da educação. Percebem ambos que a tendência à burocratização afeta diretamente a produção de conhecimento. Por isso, explicitam a resistência em acreditar na capacidade emancipadora da educação em um sistema educacional burocraticamente estruturado.

Ambos conviveram com o regime militar. Porém, para Tragtenberg esse período foi de longe muito mais problemático, pois implicou uma intervenção direta em sua atividade docente, intelectual e política. Ambos são fortemente influenciados pelas ideias e práticas políticas de oposição ao Estado autoritário, entretanto não caem na fascinação ingênua do discurso das elites políticas dos partidos comunistas. Tragtenberg foi inclusive confrontado pelos partidos por sua posição claramente contrária à burocratização e à violência empreendida por partidos de esquerda em nome da luta a favor do proletariado. Ambos perceberam que tais regimes políticos não passavam de empulhação ideológica ou de um regime baseado no capitalismo de Estado. Por esse motivo, veem na burocracia desses regimes políticos os mesmos pressupostos burocráticos instituídos nos países capitalistas autoritários. 
Na trajetória política e acadêmica de Tragtenberg, percebe-se um ecletismo em relação às leituras que influenciam diretamente a sua produção e militância. $\mathrm{O}$ anarquismo e o marxismo estão permanentemente presentes nas suas obras, ao longo da sua trajetória acadêmica, e em suas atuações políticas. Marx, Weber e alguns intelectuais anarquistas (TRAGTENBERG, 1978) acompanham permanentemente seus escritos, seja de forma direta, como objeto de análise, ou indiretamente, na estruturação dos fundamentos e das argumentações.

$\mathrm{Na}$ trajetória de Prestes Motta, percebem-se pelo menos três momentos distintos, explícitos em sua produção acadêmica: primeiro, a influência de autores como Marx e Weber (PRESTES MOTTA, 1989, 1990, 2001); segundo, o interesse pelos estudos sobre cultura organizacional e cultura brasileira (PRESTES MOTTA e CALDAS, 1997); terceiro, a influência da teoria da psicanálise (PRESTES MOTTA e FREITAS, 2002). Prestes Motta buscou, nas produções acadêmicas, respostas para suas inquietações pessoais (FARIA, 2003). Avaliando-se o desenvolvimento teórico em relação à burocracia, é possível perceber que o conceito, mesmo na segunda e na terceira fases, e apesar de não ser abordado como objeto central, está presente tangencialmente nos escritos, e em muitos deles como pressuposto elementar de estruturação social.

Tanto para Tragtenberg como para Prestes Motta, a burocracia deve ser entendida em seu espaço e tempo históricos. Essa realidade pode ser percebida em diversas formações sociais sob variadas formas de economia. Assim, as formas específicas de burocracia só podem ser entendidas em um contexto econômico e político indissociável. Burocracia é mais do que um termo pontual ou um fenômeno específico do sistema de capital. É um processo de racionalização peculiar e que se apresenta em todas as épocas históricas. Por isso, é necessário compreender sua dimensão semântica, compreender esse processo como consequência elementar do processo civilizatório. Sua compreensão requer, igualmente, dissociá-la da sua imersão ideológica e cultural, apesar desses elementos serem também constitutivos do próprio processo de racionalização de uma época histórica.

Tragtenberg e Prestes Motta concordam que as principais características da burocracia são a impessoalidade, o formalismo e o profissionalismo, apesar de as conceberem como efeitos de um processo de racionalização ocorrido na sociedade, especialmente originado da divisão técnica do trabalho. Assim, avaliando-se o conceito ao longo das suas obras, a burocracia apresenta-se como organização, poder e controle.

Burocracia como organização, porque está baseada em uma racionalidade formalizadora de natureza instrumental, estruturada na forma como o trabalho se organiza. A divisão técnica e social do trabalho estabelece a forma como as outras dimensões da vida influenciam o cotidiano dos indivíduos. A burocracia é organização porque está baseada em uma ordem específica que precisa ser compartilhada e reproduzida para garantir a existência da própria civilização. Assim, desde a organização estabelecida na forma como se estrutura a divisão técnica do trabalho para a subordinação da existência dos homens até a burocracia no interior do Estado, enquanto grande organização que assegura a continuidade do processo civilizatório na modernidade, a burocracia é vista não como produto, mas como processo de racionalização. Esse é o entendimento tanto de Tragtenberg como de Prestes Motta.

Burocracia como poder, porque sua condição de estabelecer relações de dominação, seja formatando as relações sociais ou instituindo a informalidade em favor de elites que detêm o aparelho burocrático, possibilita a reprodução dos indivíduos nas suas posições sociais ou das organizações na lógica de dominação política e econômica. A burocracia, como racionalidade instituída e mediadora de relações políticas e econômicas, apresenta-se como espaço das lutas sociais. Entretanto, esse espaço beneficia aqueles que detêm o domínio desse espaço e que têm a posse dos meios de criação e instituição das racionalidades. Sendo o poder um atributo coletivo, de grupos organizados, a burocracia torna-se instrumento de dominação e de controle social. A superioridade técnica da burocracia moderna possibilita o estabelecimento do poder. A adoção da técnica e de seu permanente aprimoramento faz da burocracia um sistema de dominação baseado na reprodução da dominação da natureza, inclusive do homem em relação ao próprio homem. As diferenças entre Tragtenberg e Prestes Motta indicam que o primeiro dirigiu suas análises para o poder do Estado, enquanto o segundo analisa a burocracia como poder emanado das organizações. Isso não implica afirmar que ambos não tenham feito a relação dialética entre poder e burocracia com base na relação entre organizações e Estado.

Burocracia como controle, porque suas formas estão presentes nas organizações produtivas e no Estado. Nesse sentido, o Estado é compreendido como a organização em forma de máquina que garante $\mathrm{o}$ 
controle político-social, influenciando diretamente a reprodução das demais organizações na sociedade. A burocracia é capaz de estabelecer relações de controle, seja por vias objetivas ou pelo domínio intersubjetivo. A tecnologia que se emprega no interior da racionalidade burocrática, bem como as normas, as regras formais e os procedimentos são exemplos de meios instituintes de controle. Agregada à ideologia, a burocracia é capaz de criar costumes, normas informais, ideias e imaginários, tornando-se responsável pelo controle intersubjetivo. Segundo os argumentos desenvolvidos nos estudos de Prestes Motta, o salário, o disciplinamento dos trabalhadores no ambiente de trabalho e a cooptação ideológica são instituidores de controle no cotidiano dos indivíduos. Por isso, a alienação se confirma na medida em que e o indivíduo interioriza o modo burocrático de pensar. A relação entre burocracia e alienação é, então, ressaltada. A inculcação ideológica, a submissão, os comportamentos padrão e o disciplinamento não são decorrentes apenas da forma objetiva como a burocracia se institui na organização. A burocracia investe também no controle intersubjetivo, e esse movimento é essencial para que o controle possa ser efetivo.

Nos estudos de Tragtenberg e de Prestes Motta, é possível perceber nuances em relação à burocracia como organização, poder e controle. Em cada um deles, a burocracia das organizações (privadas ou públicas) ou do Estado pode ser percebida como resultado de uma forma específica de organização da produção da vida dos sujeitos. Ergue-se um grande aparelho com todas as suas racionalidades fundamentais capaz de estabelecer a organização, o poder e o controle sobre as práticas dos indivíduos ou dos grupos que participam das formas organizadas de produção e de ação política. Em síntese, o presente estudo indica que, tanto nos trabalhos de Tragtenberg como nos de Prestes Motta, a burocracia apresenta-se em três formas: organização, poder e controle. Essa orientação irá inspirar diversos estudos no campo das organizações, tais como as análises críticas, a economia política do poder e a psicodinâmica do trabalho.

\section{REFERÊNCIAS}

ACCIOLY, D. Tema e variações em Maurício Tragtenberg. In: ACCIOLY, D; MARRACH, S. Mauricio Tragtenberg: uma vida para as ciências humanas. São Paulo: Editora Unesp, 2001.

CAMPOS, E. (Org) Sociologia da burocracia. Rio de Janeiro: Zahar, 1978.

ETZIONI, A. (Org) Organizações modernas. São Paulo: Atlas, 1973.

ETZIONI, A. Análise comparativa das organizações complexas. Rio de janeiro: Zahar; São Paulo: Edusp, 1974.

FARIA, J. H. Weber e a sociologia das organizações. São Paulo: Revista de Administração, v. 18, n. 2, p. 23-29, abril-junho, 1983.

FARIA, J. H. O poder na obra de Fernando Prestes Motta. EccoS Revista Científica, v. 5, n. 1, p. 139-172, 2003.

FARIA, J. H. Economia política do poder. Curitiba: Juruá, 2004. 3 volumes.

FARIA, J. H. Gestão participativa: relações de poder e de trabalho nas organizações. São Paulo: Atlas, 2009.

HEGEL, G. W. F. Princípios da filosofia do direito. São Paulo: Martins Fontes, 2000.

HEGEL, G. W. F. Fenomenologia do espírito. Petrópolis: Vozes, 2001.

LAPASSADE, G. Grupos, organizações e instituições. Rio de Janeiro: Francisco Alves, 1977.

LAZARTE, R. Max Weber: ciência e valores. Rio de Janeiro: Cortez, 1996.

MANNHEIM, K. Ideologia e utopia. 3. ed. Rio de Janeiro: Zahar, 1976.

MARCUSE, H. A ideologia da sociedade industrial: o homem unidimensional. 6. ed. Rio de Janeiro: Zahar, 1982.

MARX, K. Manuscritos econômico-filosóficos. São Paulo: Boitempo, 2004.

MARX, K; ENGELS, F. A ideologia alemã: crítica da mais recente filosofia alemã em seus representantes Feuerbach, B. Bauer e Stiner, e do socialismo alemão em seus diferentes profetas. São Paulo: Boitempo, 2007. 
MARTIN, R. Sociologia do poder. Rio de Janeiro: Zahar, 1978.

MERTON, R. e outros. Reading in Bureaucracy. Washington: Free Press, 1952.

MÉSZÁROS, I. A teoria da alienação em Marx. São Paulo: Boitempo, 2006.

MICHELS, R. Sociologia dos partidos politicos. São Paulo: Senzala, 1968.

MORIN, E. e outros. A burocracia. Lisboa: Socicultur, 1976.

POUlANTZAS, N. Poder politico e classes sociais. São Paulo: Martins Fontes, 1977.

PRESTES MOTTA, F. C. O que é burocracia. São Paulo: Brasiliense, 1981.

PRESTES MOTTA, F. C. Burocracia e autogestão. São Paulo: Brasiliense, 1982.

PRESTES MOTTA, F. C. Teoria geral da administração: uma introdução. São Paulo: Pioneira, 1989.

PRESTES MOTTA, F. C. Organização e poder: empresa, estado e escola. São Paulo: Atlas, 1990.

PRESTES MOTTA, F. C. Teoria das organizações: evolução e crítica. 2. ed. São Paulo: Pioneira Thomson Learning, 2001.

PRESTES MOTTA, F. C. Pró-posições. Revista Quadrimestral da Faculdade de Educação, Unicamp, n. 04, p. 79-87, 1991.

PRESTES MOTTA, F. C; BRESSER-PEREIRA, L. C. Introdução à organização burocrática. São Paulo: Brasiliense, 1980.

PRESTES MOTTA, F. C; CALDAS, M. (Orgs) Cultura organizacional e cultura brasileira. São Paulo: Atlas, 1997.

PRESTES MOTTA, F. C; FREITAS, Maria Ester. (Orgs) Vida psíquica e organizações. 2. ed. Rio de Janeiro: FGV Editora, 2002.

PRESTES MOTTA, F. C; VASCONCELOS, I. F. G. Teoria geral da administração. São Paulo: Pioneira Thomson Learning, 2004.

PROUDHON, P. J. Filosofia da miséria. São Paulo: Escala, 2007. 2 v.
SENNET, R. A corrosão do caráter. Rio de Janeiro: Record, 2007.

SWINGEWOOD, Alan. Marx e a teoria social moderna. Rio de Janeiro: Civilização Brasileira, 1978.

TRAGTENBERG, M. Burocracia e ideologia. São Paulo: Ática, 1974.

TRAGTENBERG, M. Francisco Ferrer e a pedagogia libertária. Revista Educação e Sociedade, v. 2, n. 1, p. 17-49, 1978.

TRAGTENBERG, M. Trabalhador não ganha boas-festas nem feliz ano novo. Folha de S.Paulo, São Paulo, 23.12.1981a, p. 3

TRAGTENBERG, M. São Paulo pergunta. Folba de S.Paulo, São Paulo, 11.11.1981b, p. 3.

TRAGTENBERG, M. Reflexões sobre o socialismo. São Paulo: Moderna, 1986.

TRAGTENBERG, M. Administração, poder e ideologia. São Paulo: Cortez, 1989.

TRAGTEnBERG, M. Traços comuns. Folha de S.Paulo, São Paulo, 27.01.1990, p. 3.

TRAGTENBERG, M. Sobre educação, politica e sindicalismo. São Paulo: Editora Unesp, 2004.

WEBER, M. O politico e o cientista. 2. ed. Lisboa: Presença, 1973.

WEBER, M. Economía y sociedad: esbozo de sociología compreensiva. 2. ed. Ciudad de México, DF: Fondo de Cultura Económica, 1974. 2 v.

WEBER, M. Ensaios de sociologia. 5. ed. Rio de Janeiro: LTC Editora, 1982.

WEBER, M. A ética protestante e o espírito do capitalismo. São Paulo: Pioneira, 1989. 